\title{
Educação infantil em contexto não urbano: um estudo com educadoras
}

\author{
Lucivanda Cavalcante Borges \\ Universidade Federal do Vale do São Francisco - PE, Brasil \\ Dalila Castelliano de Vasconcelos \\ Nádia Maria Ribeiro Salomão \\ Universidade Federal da Paraiba - PB, Brasil
}

\begin{abstract}
Resumo
A creche assume um papel cada vez mais relevante na dinâmica familiar e no desenvolvimento infantil. Estes serviços de atendimento à infância, como construções sociais e culturais, são também desenvolvidos a partir de concepções que cada sociedade constrói para as crianças. Neste artigo, buscou-se investigar as concepções de educadoras sobre o papel das creches não urbanas no desenvolvimento infantil. Participaram 21 educadoras de creches não urbanas do interior de Pernambuco. A partir da utilização de uma entrevista semiestruturada, os resultados mostraram que a creche tem como função suprir as necessidades básicas das crianças e estimular seu desenvolvimento. Em relação ao papel do educador, as participantes ressaltaram o estímulo ao desenvolvimento, oferecer afeto e disciplina à criança. Esses resultados apontam para a importância da formação dos educadores e valorização de seu papel profissional, considerando as características do contexto sociocultural não urbano.
\end{abstract}

Palavras-chave: Creche; Educador; Contexto não urbano.

\section{Daycare center in the non-urban context: an approach with educators}

\begin{abstract}
Daycare centers play an increasingly relevant part where family dynamics and infant development are concerned. These childhoodassistance services, as social and cultural constructions, are also developed as from conceptions built up by each society for infants. In this research, we investigated the educators' conceptions about non-urban daycare centers in relation to infant development. As many as 21 educators, all of whom from non-urban daycare centers in the countryside of the state of Pernambuco, took part in the study. Out of a semi-structured interview, results indicated that meeting the basic needs of a child and stimulating their development turns out as the target to be achieved by daycare centers. As for the educator's part, the participants highlighted stimulus to development, affection, and discipline as sought-after issues. These outcomes point to the importance of the educators' formation and a higher recognition of their professional role, as conceived non urban context characteristics.
\end{abstract}

Keywords: Daycare center; Educator; Non-urban context.

\section{Guardería en contexto no urbano: un estudio con educadores}

Resumen

La guardería tiene un papel cada vez más importante en la dinámica familiar y en el desarrollo infantil. Estos servicios de atención a la infancia, como construcciones sociales y culturales, se desarrollan a partir de las concepciones que cada sociedad construye para los niños. En este artículo, hemos tratado de investigar las concepciones de las maestras sobre el papel de las guarderías no urbanas en el desarrollo infantil. Participaron 21 maestras de las guarderías no urbanas del interior de Pernambuco. Con una entrevista semiestructurada, los resultados mostraron que la función de guardería es para satisfacer las necesidades básicas de los niños y fomentar su desarrollo. En cuanto al papel del educador, las participantes destacaron el fomento del desarrollo, ofrecer cariño y disciplina a los niños. Estos resultados apuntan a la importancia de la formación de educadores y la valoración de su rol profesional, entendidos desde el contexto sociocultural no urbano.

Palabras clave: Guardería; Educador; Contexto no urbano. 


\section{Introdução}

O surgimento das creches foi impulsionado no século XX pelas transformações econômicas, políticas e sociais que levaram a novas organizações familiares, sobretudo no que se refere ao papel social da mulher em relação aos afazeres domésticos, cuidado dos filhos e inserção no mercado de trabalho (Vieira, Hansen, \& Vieira, 2009). A preocupação com a saúde e higiene da população pobre também foi um importante propulsor da criação das creches. Em função dessas demandas, seu objetivo era prestar assistência às crianças das camadas pobres da população, por meio de alimentação, cuidado e saúde (Pacheco \& Dupret, 2004). No ano de 1996, a Lei de Diretrizes e Bases da Educação Nacional (Brasil, 1996) modificou o enfoque assistencialista da creche para o enfoque educativo, inserindo-a na primeira etapa da educação básica para atendimento a crianças de zero aos quarenta e sete meses de idade, quer sejam instituições públicas, quer sejam privadas. Dentre os fatores que contribuíram para esse novo modelo de atendimento à infância, destacam-se a Constituição de 1988, o Estatuto da Criança e do Adolescente- ECA (Brasil, 1990), assim como as pesquisas na área da Psicologia, Educação e Sociologia.

Desse modo, a educação infantil, outrora caracterizada pelo modelo substituto materno para as crianças pobres, passa a ser compreendida enquanto contexto educativo que atende a sujeitos de direitos (Silva \& Souza, 2014). A concepção de criança como sujeito ativo e participativo, capaz de aprender e transformar sua cultura conduziu também a novas propostas pedagógicas, caracterizando a creche como um serviço de atendimento para todas as crianças, com o objetivo de cuidar delas e educá-las de forma indissociável, complementando o trabalho da família. A indissociabilidade entre cuidar e educar envolve, além dos aspectos físicos da criança, o respeito e o estímulo ao seu desenvolvimento integral, com a garantia de uma educação de qualidade, que considere suas diferentes necessidades e formas de apropriação e participação na cultura; a parceria entre educação infantil e família, valorizando seus saberes e experiências (Brasil, 2010).

Como ressaltam Gomes, Silva e Ern (2003), o binômio cuidar/educar implica o desenvolvimento de ações que proporcionem, a todo instante, estimulação visual, olfativa, gustativa, tátil, auditiva, bem como oportunizar sua socialização. Desse modo, à medida que se disponibilizam cuidados à criança é posta em prática uma ação educativa. É nessa perspectiva integral do cuidar/educar que Moreira e Lordelo (2002) consideram a creche como uma estratégia de elevação da qualidade de vida da população, sobretudo das camadas sociais pobres, na medida em que contribui como uma rede de apoio social e econômico às famílias, à redução da violência doméstica, elevação da escolaridade e reorganização de valores e práticas de criação dos filhos. Ressaltam que, pelo fato de a criança passar o dia na creche, diminui-se o tempo de trabalho da família com a mesma, contribuindo na redução do nível de estresse materno, melhorando as interações entre mãe e criança. Contudo, como assinalam Pacheco e Dupret (2004), as creches públicas brasileiras, em sua maioria, funcionam de forma precária, com escassez de recursos, pouca infraestrutura e falta de qualificação profissional dos educadores. De acordo com esses autores, grande parte dos profissionais que trabalham nas creches públicas brasileiras tem baixa formação profissional e pautam sua prática, sobretudo, no modelo de atendimento aos cuidados básicos como higiene e alimentação. Esse caráter assistencialista contribui para o empobrecimento e não para a promoção do desenvolvimento da criança. Para esses autores, no caso das famílias que vivem em condições precárias de vida, a creche se torna fundamental no rompimento das práticas mantenedoras da exclusão social.

Cró e Pinho (2011) destacam a importância da qualidade do contexto e do atendimento dispensado pelas creches no processo educativo. Além disso, esses autores reivindicam o planejamento da prática pedagógica, baseada em uma formação sólida que considere as necessidades e os interesses das crianças, como critérios fundamentais para a garantia da qualidade do processo educativo. Esses autores (2011) realizaram uma pesquisa com educadoras de creches em Portugal, sobre os sentidos que essas profissionais atribuem a sua prática profissional. Os resultados mostraram que a maioria das educadoras não opta pela profissão que exerce e considera importante o educador possuir competências e saberes específicos para o desempenho de suas funções. Essas participantes apontaram como principais funções do educador na creche: promover as primeiras manifestações de autonomia, organizar e gerir o ambiente educativo, planejar atividades pedagógicas, estabelecer uma rotina diária e prestar cuidados básicos às crianças. No contexto brasileiro, estudos como os de Bezerra e Soares-Silva (2008), Oliveira, Silva, Cardoso e Augusto (2006), também mostraram que o exercício dessa profissão não foi uma escolha destes profissionais, mas a oportunidade que surgiu para o desempenho de um serviço remunerado.

Destaca-se, também, a pesquisa realizada por Coelho (2009) sobre a compreensão de educadoras em relação às práticas educativas na creche. Os resultados mostraram que as participantes apontaram como objetivos educacionais: a indissociabilidade 
entre cuidar e educar, a importância da estimulação, com ênfase nos processos de aprendizagem, o estabelecimento de limites e a organização da rotina na creche. Sobre o currículo da creche, a maior parte das educadoras apresentou uma perspectiva maturacional do desenvolvimento, apesar de se mostrarem sensíveis ao papel ativo que as crianças desempenham nesse processo. Conforme Coelho, as educadoras exprimem dificuldades em sua prática profissional e sentem a necessidade de referências que possam contribuir para a superação de tais desafios. Relativamente aos contextos não urbanos, onde o número de creches ainda é escasso e a qualidade de seu funcionamento precário (Silva, Pasuch, \& Silva, 2012), a importância dessa instituição enquanto contexto para o desenvolvimento infantil se torna um desafio a ser alcançado. Dados do Ministério da Educação e o Ministério do Desenvolvimento Agrário (Brasil, 2009a) mostram que, em 2005, as crianças de 0 a 6 anos do campo estavam praticamente excluídas da educação infantil. Essa exclusão devese, sobretudo, à escassez de creches nesse contexto. Ademais, o Censo Escolar de 2010 (Brasil, 2014) constatou uma maior defasagem etapa/idade $(46,6 \%)$ das crianças que frequentam a creche em contexto rural, sobretudo nas regiões Norte e Nordeste.

Rosemberg e Artes (2012) chamam a atenção para a importância de se considerar a construção do significado que se atribui à creche, se está alicerçado na compreensão desse contexto como "uma etapa educacional legítima, um direito de todas as crianças de 0 a 3 anos", ou se persiste o significado da creche associado à assistência, ou ainda, se as vagas para crianças de 0 a 03 anos de idade estão sendo preenchidas por crianças maiores, especialmente em estabelecimentos de educação infantil, denominados e registrados como creches. A esse respeito, o estudo de Martins (2006), com famílias em uma comunidade rural do município de Santa Catarina, com o objetivo de conhecer as expectativas de famílias sobre a educação dos filhos, no âmbito dos contextos de educação pública e no âmbito familiar, mostrou que a mãe é a principal cuidadora das crianças de zero a quatro anos de idade. Os resultados mostraram também que grande parte das famílias conhecia o direito da criança à creche, embora uma menor parcela dessas famílias desconhecesse que esse direito contempla também o contexto rural. Para essas famílias, as creches são importantes para que os pais possam trabalhar, assim como também constituem espaços para a educação das crianças.

Pode-se afirmar que os serviços de atendimento à infância são desenvolvidos a partir de concepções e expectativas que cada sociedade constrói para as crianças e ajudam a configurar as práticas de cuidado e educação ideal (Harkness \& Super, 2013). Estudos (Harkness \& Super, 1992; Musatti, 2003) têm mostrado que pais e educadores de diversas culturas assumem perspectivas diferentes quando avaliam os aspectos ligados à organização do ambiente educativo nas instituições, ao comportamento, à qualificação e ao desempenho dos educadores ou especificamente à dimensão curricular. Ademais, as concepções sobre desenvolvimento e educação estão relacionadas com a organização do contexto físico e social e com a forma como os educadores conduzem suas práticas educativas. Por sua vez, tais processos são construídos por meio da interação sociocultural do indivíduo e apresentam variações entre contextos (Harkness \& Super, 2013).

Partindo do pressuposto de que a creche apresenta relevância para o desenvolvimento infantil e que as concepções dos educadores em relação a esse contexto podem influenciar sua prática profissional, o presente artigo objetiva investigar o que pensam as educadoras sobre o papel das creches não urbanas no desenvolvimento infantil. Busca, assim, compreender o impacto que essa instituição educativa oferece à criança e às suas famílias, no contexto estudado.

\section{Método}

\section{Participantes}

Participaram desta pesquisa 21 educadoras de duas creches, situadas em dois contextos não urbanos, acerca de $25 \mathrm{~km}$ de um município do interior de Pernambuco. Todas as educadoras residiam nos contextos onde estavam localizadas as creches estudadas.

\section{Contexto da pesquisa}

Os contextos onde se situam as creches são caracterizados pela expressiva produção de agricultura para exportação, onde os pais das crianças trabalham como empregados na lavoura, assim como agricultura de subsistência que sustenta muitas famílias desses contextos. Esses contextos apresentam casas próximas uma das outras, com ampla área externa e arborizada; mercado, igreja e escolas. As creches situavam-se na parte mais central da comunidade. Estas instituições educativas correspondem a um programa que integra as políticas de saúde, a assistência social e educação infantil e integram um modelo alternativo de atendimento às crianças e às suas famílias, em situação de vulnerabilidade social. As creches em que esta pesquisa foi realizada foram criadas entre os anos de 2012 e 2013. As atividades da creche começam às 6 h00 horas e terminam às $18 \mathrm{~h} 00$ horas. Esse horário corresponde ao horário de trabalho da maioria dos pais do contexto não urbano estudado, o horário de ida e volta do trabalho 
na roça. Em relação à estrutura física, as creches estudadas apresentavam quatro salas correspondentes às faixas etárias das crianças: berçário, com 05 crianças de 04 a 11 meses; maternal I, com 10 crianças entre 12 e 23 meses; maternal II, com 20 crianças de 24 a 47 meses; e a pré-escola, com 16 crianças de 48 a 72 meses. As creches contavam, ainda, com dois banheiros, um masculino e outro feminino; cozinha; refeitório; área externa para recreação, com chuveiros para banho ao ar livre e cantinho de areia. Possuía livros de histórias e brinquedos educativos, assim como decorações com desenhos, materiais pedagógicos e atividades dos alunos nas paredes das salas. A proposta pedagógica das creches é baseada nos princípios da educação infantil do Instituto Alfa e Beto (IAB), cujo objetivo é promover o desenvolvimento integral da criança, nos aspectos pessoal, social, cognitivo e psicomotor. $\mathrm{O}$ acesso das crianças à creche ocorre pela oferta de vagas e interesse dos pais em colocar seu filho nestas instituições. No entanto, a demanda ainda é maior que a oferta do número de vagas.

\section{Instrumentos}

Para conhecer as concepções das educadoras sobre o seu papel como educador e a função da creche no desenvolvimento infantil de crianças não urbanas, foi utilizada uma entrevista semiestruturada composta por dez questões divididas em quatro eixos temáticos: concepções de desenvolvimento infantil; concepções sobre creche e papel do educador; prática de cuidado/interação com a criança e metas de socialização. Para o presente estudo, considerou-se o eixo das questões sobre as concepções de creche e o papel do educador. Também foi utilizado um questionário sociodemográfico para coletar informações como idade, escolaridade, renda familiar, estado civil, tempo de trabalho na creche.

\section{Procedimentos}

Inicialmente, o referido projeto foi submetido ao comitê de ética em pesquisa com seres humanos da Universidade Federal da Paraíba, conforme resolução 196/96-versão 2012, sobre pesquisas envolvendo seres humanos e aprovado sob número 22655413.0.0000.5188. Em relação à coleta de dados, primeiramente, manteve-se contato com a secretaria do programa responsável pelas creches para obter informações sobre a localização dessas e solicitar autorização para realizar a pesquisa nesses contextos. Após o consentimento da secretária responsável, foi realizada uma primeira visita às creches para formalizar, junto à coordenação, a pesquisa nessas instituições. A partir de então, foi apresentado o objetivo da pesquisa e feito o convite às educadoras para participarem da mesma. Para aqueles que aceitaram participar da pesquisa foi-lhes apresentado o Termo de Consentimento Livre e Esclarecido (TCLE), o qual foi assinado por cada um dos participantes. Cada participante foi informado sobre os objetivos da pesquisa, sua confidencialidade e o caráter voluntário da mesma.

A entrevista semiestruturada foi realizada de forma individual e audiogravada por meio de gravadores digitais. Os dados foram tratados a partir da análise de conteúdo qualitativa e quantitativa (Bardin, 1977/2010) e, posteriormente, submetidos ao cálculo percentual, com base no número total de respostas da categoria. A etapa da análise qualitativa compreendeu os processos de pré-análise, exploração e tratamento do material obtido e interpretação dos mesmos, conforme a literatura estudada e os objetivos da pesquisa. Assim, inicialmente, foi realizada a leitura flutuante do material construído por meio da entrevista. A seguir, foram construídas categorias, organizadas conforme a frequência de respostas semanticamente semelhantes ou divergentes, considerando a exaustividade, representatividade, homogeneidade e pertinência. Essas categorias, por sua vez, foram divididas em subcategorias não excludentes. O processo de categorização foi desenvolvido por dois juízes, apresentando um índice de $94 \%$ de concordância entre ambos, o que sugere uma forte confiabilidade, considerando-se o número de categorias analisadas.

\section{Resultados e Discussão}

\section{Dados sociodemográficos das educadoras}

A Tabela 1 apresenta os dados sociodemográficos das educadoras participantes desta pesquisa.

TABELA 1

Dados sociodemográficos das educadoras

\begin{tabular}{llcr}
\hline \multicolumn{2}{c}{ Dados sociodemográficos } & $f$ & $\%$ \\
\hline \multirow{3}{*}{ Idade } & 19-29 anos & 13 & 61,9 \\
& 30-40 anos & 06 & 28,6 \\
\multirow{3}{*}{ Escolaridade } & 41-51 anos & 02 & 9,5 \\
& 2o grau & 12 & 57,1 \\
Tempo de trabalho completo & 05-12 meses & 09 & 42,9 \\
na creche & 13-20 meses & 08 & 38,1 \\
& 21-28 meses & 07 & 33,3 \\
\multirow{4}{*}{ Estado civil } & Solteira & 06 & 28,6 \\
& Casada & 09 & 42,9 \\
\multirow{3}{*}{ Renda familiar } & União estável & 07 & 33,3 \\
& Até 01 salário mínimo & 05 & 23,8 \\
\multirow{5}{*}{ Religião } & 01 salário e meio a 02 salários & 17 & 81 \\
& Católica & 13 & 19 \\
& Evangélica & 07 & 33,3 \\
& Não tem & 01 & 4,7 \\
\hline
\end{tabular}


A idade das educadoras variou entre 19 e 45 anos, com média de 26 anos. A maioria era solteira (42,9\%), possuía o 2 o grau completo $(57,1 \%)$ e a religião católica (62\%). De acordo com a Lei de Diretrizes e Bases da Educação - LDB (Brasil, 1996), os educadores de creche devem ser formados em curso superior ou formados por treinamento em serviço. No caso das educadoras entrevistadas, menos da metade possui essa titulação, embora muitas delas estejam iniciando o curso superior. Para aqueles que ainda não possuem esse título, as diretrizes da LDB admitem que tenham, no mínimo, o diploma de magistério de ensino médio. $\mathrm{O}$ tempo de trabalho das educadoras na creche variou entre nove e 28 meses, o que representa tempo insuficiente para o contínuo acompanhamento do desenvolvimento das crianças. A rotatividade de educadores, ainda, é um problema nas instituições de educação infantil e essa realidade pode interferir na construção de vínculos de confiança entre educadores e a criança, como também no aprimoramento das atividades educativas. A renda salarial variou entre meio salário e dois salários mínimos, com média de $\mathrm{R} \$ 505,14$ (quinhentos e cinco reais e quatorze centavos), considerando o valor do salário mínimo de $\mathrm{R} \$ 724,00$ na época da realização da pesquisa de campo. As educadoras que recebiam meio salário trabalhavam meio expediente na creche. Destaca-se a baixa remuneração das educadoras das creches estudadas, fato que desvaloriza seu papel como profissional. Para Becker (2008), quanto mais nova a criança, menor o prestígio profissional e menor a remuneração das educadoras. Ainda segundo esse autor, a desvalorização desses educadores tem raízes no modelo assistencialista que deu origem às creches, modelo em que as educadoras assumiam o papel materno nos cuidados à criança. Sendo assim, à educadora, então considerada cuidadora, bastava saber cuidar de crianças, dispensando formação profissional e, consequentemente, sua remuneração seria baixa em relação aos demais profissionais da educação infantil e das outras etapas do ensino. Essa situação se repete nas creches dos contextos urbanos (Campos, Fullgraf, \& Wiggers, 2006). Todas as educadoras eram moradoras do contexto não urbano onde foi realizada a entrevista, e sua inserção na creche foi realizada por meio de contratos temporários firmados com a prefeitura do município onde as creches estão situadas.

A partir da análise das respostas das educadoras foram elaboradas duas categorias: concepções das educadoras sobre o papel da creche no desenvolvimento infantil e papel do educador no desenvolvimento da criança. Na primeira categoria foram identificadas duas subcategorias: suprir necessidades básicas e estimular o desenvolvimento da criança. A segunda categoria compreendeu três subcategorias: estímulo ao desenvolvimento infantil, dar afeto e disciplinar o comportamento da criança. Esses resultados são apresentados a seguir.

\section{Concepções das educadoras sobre o papel da creche no desenvolvimento infantil}

Em relação à importância da creche no desenvolvimento infantil, a maioria das educadoras $(60,7 \%)$ respondeu suprir necessidades básicas, como os cuidados dispensados ao infante enquanto os pais trabalham, alimentação e afeto. Ademais, de acordo com as educadoras, esses cuidados também são importantes devido a não serem dispensados pelos pais, mesmo quando presentes em casa.

"Aqui eles têm a certeza de que podem deixar, podem trabalhar tranquilos, porque não têm custo nenhum pra eles porque as crianças são muito carentes, então aqui eles têm as 5 refeições, tomam banho, que muitos em casa não tinham nada disso, às vezes passavam necessidades, e aqui eles têm a oportunidade de brincar, de estudar, de se alimentar, todas as oportunidades de se desenvolver, coisa que em casa eles não têm".

"Acho que em primeiro lugar tá o cuidado porque nem todas têm o cuidado, o cuidado tem aqui não tem em casa. A alimentação, o cuidado, o carinho, a presença dos pais. Aqui mesmo tem criança que chama a gente de mamãe, a gente diz, é titia, não é mamãe".

Esses resultados relacionam-se com aqueles encontrados por Volpato e Mello (2005) sobre a função da creche, os quais mostraram ênfase na alimentação e cuidado, e, ainda, que as educadoras se consideravam substitutas do papel maternal, como também mais aptas a desenvolvê-lo que as mães das crianças, uma vez que estas não ofereciam o cuidado, o carinho e a atenção necessários ao desenvolvimento infantil. Vê-se, pois, a ênfase no papel assistencialista da creche, como instituição que busca suprir necessidades básicas da criança, a exemplo da alimentação, cuidados físicos e afeto, substituindo o papel parental. Além disso, as concepções sobre a creche, conforme fala das educadoras entrevistadas, denotam uma desqualificação do papel da família não urbana no exercício do papel parental, considerando-a incapaz de atender às necessidades básicas dos filhos, como alimentação, cuidado e carinho. De acordo com Lima e Silva (2015), as significações negativas atribuídas 
por educadores às famílias no cuidado com os seus filhos vão além do contexto não urbano. Para essas autoras, a condição de pobreza em que se encontram essas famílias, é o principal disparador das concepções que a desqualificam. Outras pesquisas com educadores de creches também mostraram concepções negativas sobre as famílias pobres na educação dos filhos (Ramos \& Salomão, 2013; Silveira \& Wagner, 2009).

Como preconizado pela LDB (Brasil, 1996), entende-se que o cuidado, a alimentação e o carinho também devem fazer parte do cotidiano da creche; porém, enquanto instituição educativa, baseada em conhecimentos intencionalmente organizados e potencializadores dos processos de desenvolvimento e aprendizagem, a educação a ser realizada na creche vai além daquela realizada no contexto familiar. Outrossim, no que se refere à afetividade, essa faz parte do processo de ensino-aprendizagem, conferindo ao educador um papel de destaque na qualidade das trocas sociais que estabelece com a criança e, portanto, não se caracteriza como práticas assistencialistas, substitutivas do papel materno. Além de suprir necessidades, a função educativa da creche também surgiu na fala das educadoras, como um estímulo ao desenvolvimento infantil (39,3\%).

"Essa creche tem um papel fundamental na vida deles, porque antigamente só entrava na escola a partir de 04 anos, e eles chegando aqui, quando vão entrar na escola já estão bem... já conhecem as letrinhas, já estão bem informatizados, porque eles não vão aprender, a maioria até sabe, porque tem criança que aprende bem, a gente não ensina pra aprender, mas eles são tão assim, curiosos, que eles aprendem bem, tem uns que contam até 10, não é pra eles contarem até 10 nessa sala aqui, é só até 05, o meu já conta na minha sala, ele já chega bem interagindo quando vão pra escola, aqui na creche, eles aprendem mesmo aqui".

"Acho ótimo, porque quem era a criança que a mãe vai ensinar a bater uma lata, que é o desenvolvimento auditivo. Raramente, uma mãe que não tem o filho na creche vai ler pra uma criança, e a gente não, a gente tem hora pra tudo, a gente tem hora de cantiga, leitura".

As educadoras entendem que a creche poderá oferecer à criança conhecimentos não disponibilizados em casa, tendo em vista que as famílias são pobres e, em sua maioria, apresentam nível de escolaridade baixa. Por outro lado, observa-se, na fala das educadoras, que, apesar de a creche ter a função de estimular o desenvolvimento infantil, esse estímulo está condicionado a processos maturacionais da criança, na medida em que limitam suas habilidades a etapas de aprendizagem, não considerando suas potencialidades, independentemente da idade em que se encontram. Nessa perspectiva, a aprendizagem de novos conhecimentos depende da prontidão da criança e irá influenciar as práticas pedagógicas. A compreensão maturacional do desenvolvimento humano, por parte das educadoras de creche, também foi encontrada no estudo de Coelho (2009). Todavia, o desenvolvimento infantil se processa além dos aspectos biológicos, tendo em vista que esses são necessários, porém não suficientes para que a criança se desenvolva culturalmente. Ademais, esse processo não é linear, pois se constrói a partir da inserção da criança no contexto histórico e cultural (Vygotsky, 1984/2015; Asbahr \& Nascimento, 2013). Assim, a criança encontra-se imersa em um contexto sociocultural, transformando-o na medida em que é transformada por ele, participando ativamente de seu desenvolvimento e da sua aprendizagem. Nessa perspectiva, o educador é um ator fundamental no processo de aprendizagem da criança, mediando sua relação com o conhecimento, desafiando suas potencialidades e possibilitando diferentes experiências complementares às da família. Como ressaltado por Asbahr e Nascimento (2013), a escola não pode esperar que a criança amadureça para aprender; é preciso criar as condições para que a maturação aconteça.

Ao considerar o não urbano como contexto de vida, é importante ressaltar uma educação que dialogue com as características socioculturais concretas dessa realidade, com os modos de vida da infância desse lugar. Esse diálogo entre contextos é preconizado pelo Ministério da Educação (Brasil, 2009), segundo o qual o currículo da educação infantil deve ser baseado nas interações e práticas educativas intencionalmente atreladas às experiências concretas da vida cotidiana, para a aprendizagem da cultura. Apesar de ser um direito de toda a criança, não apenas daquelas cujas mães trabalham, as creches, no contexto não urbano, ainda são escassas. Silva et al. (2012) argumentam que, parte dessa concepção é fundamentada na representação saudosista e romantizada do não urbano como espaço em que família é extensa, a educação da criança é compartilhada por outros familiares e vizinhos e, portanto, as crianças não precisam da creche. Tal concepção implica a creche como lugar para cuidar das crianças e dar assistência às famílias, e não como contexto educativo.

No caso das creches estudadas, as crianças que as frequentam provêm de famílias economi- 
camente desfavorecidas, oferecer a alimentação diária é considerado um fator importante para o desenvolvimento infantil. Ademais, como observado nos resultados sobre a percepção da infância no contexto rural, para essas educadoras, a maioria das crianças não desfruta do afeto dos pais e, portanto, a creche seria uma oportunidade de construção de vínculo e afeto entre educadores e crianças, já que, para elas, o afeto é um fator importante para o desenvolvimento infantil. Como evidenciado por Moreira e Lordelo (2002), a creche representa para as camadas sociais empobrecidas uma oportunidade de elevação da qualidade de vida da população, na medida em que atua como uma rede de apoio social e econômico. Oportuniza, ainda, maior autonomia às mulheres e o seu acesso às políticas públicas, na proporção em que possibilita a sua participação no mercado de trabalho, na vida social, contribuindo para a redução da desigualdade e violência de gênero. Aponta-se ainda, que a creche nos contextos estudados pode representar um fator de proteção à criança, pois de acordo com as educadoras, muitas delas ficavam sozinhas nas ruas ou em casa de pessoas desconhecidas, para que os pais pudessem sair para trabalhar.

Além do papel social da creche na organização familiar, essa se constitui um direito de toda a criança, direito à educação pública e de qualidade. Sem desconsiderar a importância do atendimento às necessidades básicas do desenvolvimento infantil, o caráter educativo da creche não pode ser deixado em segundo plano, sobretudo devido ao fato de que educar e cuidar está intimamente associado e são objetivos priorizados na educação infantil. Decerto, para além de ser um direito a todas as crianças de 04 a 36 meses, a creche necessita apresentar critérios de qualidade, seja em que contexto for. A partir das falas das educadoras, é possível dizer que as creches estudadas exercem um impacto social na vida das crianças e de suas famílias, e que estas profissionais objetivam promover o desenvolvimento infantil. Por outro lado, destaca-se a importância da formação profissional destas educadoras, para o desenvolvimento de práticas pedagógicas e educativas que incorporem as características próprias do modo de vida das crianças e famílias do contexto onde estão inseridas.

\section{Papel do educador no desenvolvimento da criança}

De acordo com as educadoras, o educador na creche é um profissional que tem por objetivo estimular o desenvolvimento infantil (64,3\%).
"Eu acho que o principal, na minha turma, porque a faixa etária deles é deixar algum tipo de valor porque na nossa turma a gente não pode alfabetizar, a gente tem que ensinar a eles os primeiros números, no caso contar até dez, as vogais e as cores primarias. Mas a gente não tem essa função de educar mesmo na questão de professor".

"Eu trabalho a linguagem dos fonemas, não é pra eles saírem daqui lendo, mas eles terem conhecimento, faz atividades, tem o livro de atividades, tem uma tarefinha que eu faço pra os pais interagirem com eles final de semana, tem várias atividades que a gente faz com ele".

$\mathrm{Na}$ fala das educadoras, trabalhar aspectos relativos à linguagem escrita corresponde a um dos seus papeis. Porém, ao mesmo tempo, há uma preocupação com a possível escolarização precoce da criança. Desse modo, observa-se, na fala das educadoras, aspectos de uma visão maturacionista e passiva do desenvolvimento infantil, como aqueles encontrados no estudo de Coelho (2009), na medida em que a aprendizagem é vista como espontânea e sequencial, e as competências da criança são desconsideradas nesse processo, a exemplo do evitar que determinados conhecimentos, os quais já fazem parte do cotidiano extraescolar da criança, sejam-lhe expostos, por considerar que essa ainda não está "pronta" para processá-los, como o contar até dez. Esse pensamento condiz com a perspectiva de que o desenvolvimento já está predeterminado e que evolui com o tempo. Porém, é preciso considerar que, muito antes de chegarem à escola, as crianças já apresentam conhecimentos da cultura escrita, pois vivenciam no seu dia a dia o mundo letrado, por meio de gibis, livros, jornais, músicas, que correspondem às práticas sociais de uso da leitura e da escrita (Vygotsky, 1984/2015). No caso daquelas crianças em que esse contato com a cultura escrita é mais restrito, a creche e a escola representam contextos importantes para o contato com essas práticas, ao contrário de restringi-las.

Além do estímulo ao conhecimento, dar afeto (25\%) e disciplina (10,3\%) as crianças são papéis destacados pelas educadoras em sua atuação profissional. Essas respostas aproximam-se da concepção de creche como assistência às crianças pobres, seja no sentido de cuidados, alimentação, como de afeto; concepção de que as mães pobres não são capazes de cuidar e amar seus filhos, cabendo às educadoras o papel de mães substitutas e à creche o papel de suprir necessidades humanas básicas, numa perspectiva higienista. As diretrizes curriculares nacionais para a Educação Básica (Brasil, 2013), orientam que os educadores 
compreendam sua atuação profissional como uma parceria com o trabalho das famílias na educação das crianças, considerando que cada contexto tem suas especificidades na criação de diferentes ambientes e papéis para seus membros. Carvalho (2014) chama a atenção para a ênfase atribuída ao afeto na caracterização do trabalho docente. Segundo essa autora, à luz da pedagogia da infância, a afetividade tem-se tornado um estereótipo para qualificar o docente como bom profissional, constituindo um elemento definidor da vocação do indivíduo para o exercício da docência, e o professor passou a ser visto como naturalmente afetivo. Para Carvalho, tais estereótipos surgiram a partir das supostas teorias sobre a privação de afeto das famílias em relação aos seus filhos, cabendo ao professor suprir essa necessidade. Com esses argumentos, a autora não pretende desqualificar o papel do afeto no processo de aprendizagem e desenvolvimento infantil. O que preocupa, segundo ela, são a naturalização e supremacia atribuídas ao afeto no exercício da docência, em que a formação do professor, assim como os processos históricos e culturais que a sustentam, são desconsiderados. Dessa forma, o afeto continua sendo um elemento importante para o desenvolvimento e a aprendizagem da criança, mas não pode ser imposto ao educador como um atributo natural para o exercício da docência, desqualificando sua formação e conhecimentos teóricos práticos.

"A gente tem que dar um pouco de si, do que a gente tem pra cada uma delas, e o que elas mais necessitam, eu creio, é esse carinho, esse afeto, que a gente tira da gente pra dar a elas porque há muita carência, porque é muito pouco tempo que elas passam com as mães, no final de semana, porque é muita correria (...)”.

“(...) A nossa função mesmo é questão de disciplina, de eles saberem o que é certo e o que é errado. Então eu acho que é fundamental o nosso papel porque nessa faixa etária é onde a criança tem a capacidade de absorver tudo o que é passado pra ela, porque a gente sabe que depois dos 7 anos a personalidade deles já tá formada, então, tudo o que a gente puder colocar neles de bom nessa faixa etária (...)”.

Esse resultado corrobora aqueles encontrados por Ramos e Salomão (2013) e Almeida e Cunha (2003) sobre as concepções de educadores a respeito do desenvolvimento infantil, os quais mostraram representações da criança como objeto de cuidado e afeto. Para Almeida e Cunha (2003), essa representação ilustra o lugar social para o qual a criança foi preparada, um lugar social ideológico, na medida em que a criança é vista como um ser desprovido, não plenamente agente, competente e responsável.

Em relação à disciplina, entendida como o estabelecimento de limites ao comportamento da criança e a aprendizagem de hábitos educativos, também reflete a concepção da criança como ser passivo, que absorve as influências do meio, além do entendimento de que há períodos específicos para a absorção desses conhecimentos. Nesse sentido, o educador, como detentor dos conhecimentos, estaria transmitindo-os às crianças, de acordo com a sua prontidão para aprender, conhecimentos esses, voltados para o ensino da disciplina e os bons costumes, que buscam o controle e moralização das crianças. A importância atribuída à disciplina, ao controle do comportamento infantil expressa uma relação desigual de poder, em que a passividade e obediência da criança são comportamentos valorizados pelos professores e incentivados na interação. A concepção de que a disciplina é um dos objetivos da educação infantil foi encontrada em muitas pesquisas com educadores da educação infantil (Gomes, 2008; Jorge, Reis, \& Nascimento, 2008; Ramos \& Salomão, 2013).

\section{Considerações Finais}

A creche exerce um papel significativo no desenvolvimento infantil. As experiências vivenciadas pela criança nesse contexto ampliam seu processo de socialização e aprendizagem, e, sobretudo, no que se refere às crianças que vivem em contexto marcado por condições socioeconômicas precárias, a creche contribui para a superação da exclusão social. A partir dos resultados analisados neste artigo, evidencia-se o caráter assistencial atribuído ao papel das creches pelas educadoras, caracterizado pela oportunidade de suprir necessidades básicas, como alimento, cuidado com a higiene e saúde em geral. Considera-se que esses cuidados também são importantes para a criança que se encontra na creche; todavia, a função social da creche não pode se resumir aos mesmos.

Enquanto objetivo profissional, as educadoras se percebem como responsáveis pelo estímulo ao desenvolvimento infantil das crianças que estão na creche; contudo, suas falas demonstram uma concepção maturacional da aprendizagem, na medida em que consideram a necessidade de as crianças amadurecerem para adquirir determinados conhecimentos, e que a prática pedagógica não pode ir além do que a criança já adquiriu em seu desenvolvimento. Em 
outras palavras, na perspectiva das educadoras, a aprendizagem segue o resultado do desenvolvimento, e não o precede. A esse respeito, Vygotsky (1984/2015) defende que a aprendizagem escolar orienta e ativa os processos internos de desenvolvimento. Além disso, para as educadoras, no desempenho de seu papel profissional, destaca-se a compensação das carências afetivas que atribuem às crianças que frequentam as creches estudadas. Para essas entrevistadas, os pais não estariam provendo a atenção e o carinho necessários às crianças, pois passam a maior parte do tempo trabalhando e, mesmo quando estão em casa, não dispõem de tempo para os filhos, como também, muitos não são carinhosos com estes. Logo, caberia a elas, educadoras, enquanto profissionais capacitadas para o desempenho de sua profissão oferecer-lhes o afeto e a atenção que precisam. Esse resultado expressa a concepção de que as crianças pobres são carentes não só economicamente, como também afetivamente, o que condiz com a perspectiva da educação compensatória. Outrossim, as concepções desses profissionais em relação ao seu contexto de trabalho têm relação com as práticas educativas realizadas com as crianças (Harkness \& Super, 2013). Nesse sentido, a capacitação profissional pode contribuir com conhecimentos sobre o desenvolvimento da criança, seus direitos e suas necessidades, tendo em vista que é, sobretudo na interação com os educadores, que seu desenvolvimento é influenciado de forma intencional, e a qualidade das interações, as atividades planejadas, a organização do cotidiano da creche, estão atreladas a sua formação profissional.

No caso das educadoras entrevistadas, destacase que sua formação, apesar de nível de escolaridade médio e elevado, de um modo geral, foi realizada em períodos curtos de tempo, como nos fins de semana, fato que pode comprometer a qualidade da mesma. Além disso, como observado nos dados sociodemográficos, as educadoras apresentaram pouco tempo de trabalho nas creches estudadas, caracterizando uma rotatividade destas profissionais, trazendo implicações para as relações educador/criança, assim como para o processo educativo. Cabe ressaltar, ainda, a necessidade de valorização do papel do educador, das melhorias nas condições de trabalho e em sua remuneração salarial, tendo em vista os baixos salários que recebem. É importante mencionar também algumas limitações do presente estudo, como o conhecimento das famílias das crianças da creche e a metodologia utilizada. Assim, como sugestões para futuras pesquisas no contexto não urbano, aponta-se a importância de conhecer as características sociodemográficas dos pais das crianças da creche, além do uso da observação sistemática para estudar a relação entre as concepções das educadoras e as práticas educativas por elas apresentadas no trabalho com as crianças nas creches.

\section{Referências}

Almeida, A. M. O. \& Cunha, G. G. (2003). Representações sociais do desenvolvimento humano. Psicologia: Reflexão e Critica, 16(1), 147-155. http://dx.doi.org/10.1590/s0102-79722003000100015

Asbahr, F. S. F. \& Nascimento, C. P. (2013). Criança não é Manga, não Amadurece: conceito de maturação na teoria históricocultural. Psicologia: Ciência e Profissão, 33(2), 414-427. http://dx.doi.org/10.1590/s1414-98932013000200012

Bardin, L. (2010). Análise de conteúdo. Lisboa: Edições 70.

Becker, F. da R. (2008). A educação infantil no Brasil: a perspectiva do acesso e do financiamento. Revista Iberoamericana de Educación, 47, 141-155.

Brasil. (2014). INEP/MEC. Instituto Nacional de Estudos e Pesquisas Educacionais Anísio Teixeira. Censo Escolar da Educação Básica - Caderno de Instrução. Disponível em: http: //www.portal.inep.gov.br/básica-censo.

Brasil. (2013). Ministério da Educação. Secretaria de Educação Básica. Secretaria de Educação Continuada, Alfabetização, Diversidade e Inclusão. Secretaria de Educação Profissional e Tecnológica. Conselho Nacional da Educação. Câmara Nacional de Educação Básica. Brasília: MEC, SEB, DICEI.

Brasil. (2009a). Ministério da Educação. Programa Mais Educação - passo a passo por Maria Eliane Santos et al. Brasília: MEC - Secad. Disponível em: http://www.portal.mec.gov.br/dmdocuments/passoapasso_maiseducacao.pdf. Acesso em 30 de setembro de 2015.

Brasil. (1996). Lei de Diretrizes e Bases da Educação Nacional. Lei no 90394/96 de 20 de dezembro. http://www.ffclrp. usp.br/graduacoes/estagio/legislacao/lein9394.pdf. Acesso em 15 de outubro de 2015.

Brasil. (1990). Estatuto da Criança e do Adolescente: Lei Federal no 8069, de 13 de julho de 1990. Rio de Janeiro: Imprensa Oficial, 2002.

Campos, M. M., Fullgraf, J., \& Wiggers, V. (2006). A qualidade da educação infantil brasileira: alguns resultados de pesquisa. Cadernos de Pesquisa, 36, 127, 87-128. http://dx.doi.org/10.1590/S0100-15742006000100005

Carvalho, R. S. (2014). O imperativo do afeto na educação infantil: a ordem do discurso de pedagogas em formação. Educação e Pesquisa, 40(1), 1-16. http://dx.doi.org/10.1590/S1517-97022013005000026 
Coelho, A. (2009). Intencionalização educativa em Creche. Revista Iberoamericana de Educación, 49(5), 1681-5653.

Cró, M. L. \& Pinho, A. M. (2011). A primeira infância e a avaliação do desenvolvimento pessoal e social. Revista Iberoamericana de Educación, 56(1), 1681-5653.

Gomes, R. C. O. (2008). Concepções de mães e professoras de educação infantil. In V. Vasconcellos, L. Aquino, \& A. Dias (Ed.). Psicologia e educação infantil (p. 147-166). Araraquara: Junqueira \& Marin Editores.

Gomes, V. L. O., Silva, A. L., \& Ern, E. (2003). O cuidado de crianças em creche: um espaço para a enfermagem. Revista Gaúcha de Enfermagem, 24(2), 147.

Harkness, S. \& Super, C. (2013). Cultura e política no desenvolvimento na primeira infância. In R. E. Tremblay, M. Boivin, \& R. D. V. Peters (Eds), Enciclopédia sobre o Desenvolvimento na Primeira Infância [on-line]. Montreal, Quebec: Centre of Excellence for Early Childhood Development e Strategic Knowledge Cluster on Early Child Development. Disponível em: http://www.enciclopedia-crianca.com/documents/Harkness-SuperPRTxp1.pdf

Harkness, S. \& Super, C.M. (1992). The developmental niche: A theoretical framework for analyzing the household production of health. Social Science and Medicine, 38, 217-226. http://dx.doi.org/10.1016/0277-9536(94)90391-3

Jorge, A S., Reis, A. C., \& Nascimento, C. S. P. (2008). Práticas cotidianas e concepções de desenvolvimento de professoras da educação infantil. In V. Vasconcellos, L. Aquino, \& A. Dias (Ed.), Psicologia e educação infantil (pp. 71-94). Araraquara: Junqueira \& Marin Editores.

Musatti, T. (2003). Programas educacionais para a pequena infância na Itália. Revista Brasileira de Educação, 24, 66-77. http://dx.doi.org/10.1590/s1413-24782003000300006

Maranhão, D. G. (2000). O cuidado como elo entre saúde e educação. Cadernos de Pesquisa, 111, 115-133. http://dx.doi. org/10.1590/S0100-15742000000300006

Moreira, L. V. C. \& Lordelo, E. R. (2002). Creche em ambiente urbano pobre: ressonâncias no ecossistema desenvolvimental. Interação em Psicologia, 6(1), 1-13. http://dx.doi.org/10.5380/psi.v6i1.3189

Pacheco, A. L. P. \& Dupret, L. (2004). Creche: Desenvolvimento ou sobrevivência? Psicologia USP, 15(3), 103-116. http://dx.doi.org/10.1590/S0103-65642004000200006

Ramos, D. D. \& Salomão, N. M. R. (2012). Interação educadora-criança em creches públicas: estilos linguísticos. Psicologia em Estudo, 17(1), 15-25. http://dx.doi.org/10.1590/S1413-73722012000100003

Rosemberg, F. \& Artes, A. (2012). O rural e o urbano na oferta de educação para crianças de até 6 anos. In Barbosa, M. C. S. et al. (Org.), Oferta e demanda de educação infantil no campo (pp. 13-69). Porto Alegre: Evangraf.

Silva, A. P. S. \& Souza, T. N. (2014). Educación de ni-os y ni-as de 0 a 5 a-os em brasil: retos para la política y práctica de la educación infantil en el medio rural. Tabanque Revista pedagógica, 27, 65-82.

Silva, A. P. S., Pasuch, J., \& Silva, J. B. (2012). Educação infantil do campo. São Paulo: Cortez.

Volpato, C. F. \& Melo, S. A. (2005) Trabalho e Formação dos Educadores de creche em Botucatu: Reflexões críticas. Cadernos de Pesquisa, 35(126), 723-745. http://dx.doi.org/10.1590/s0100-15742005000300010

Vygotsky, L. S. (1984/2015). A formação social da mente (7ạ ed.). São Paulo: Martins Fontes.

\footnotetext{
Autores:

Dalila Castelliano de Vasconcelos - Mestre, Universidade Federal da Paraíba.

Nádia Maria Ribeiro Salomão - Doutora, Universidade Federal da Paraíba.

Endereço para correspondência:

Lucivanda Cavalcante Borges

Rua José de Sá Maniçoba, s/no - Campo Universitário - Centro

56304-917 Petrolina, PE, Brasil

Recebido em: 29.11.2015

Aceito em: 27.05.2016
}

Lucivanda Cavalcante Borges - Doutora, Universidade Federal do Vale do São Francisco. 